\title{
PSYCHE
}

\begin{tabular}{lll}
\hline Vol. L Sept.-DeC., 1943 & Nos. 3-4 \\
\hline
\end{tabular}

\section{BIONOMICS OF ECTOPSOCUS PUMILIS (BANKS) (CORRODENTIA, CÆCILIIDÆ) ${ }^{1}$}

\author{
By Kathryn M. Sommerman ${ }^{2}$ \\ University of Illinois, Urbana, Ill.
}

Two species of Ectopsocus have been recorded from the United States: E. pumilis (Banks) and E. californicus (Banks). The former has been found commonly on corn (maize). Although E. californicus has been taken from the palm Areca lutescens in the greenhouses of the University of Illinois, and has been reared for several generations in the laboratory on corn sheaths, it has not been found in the cornfields.

$E$. pumilis has been recorded previously from New York, Virginia, North Carolina, Georgia, Florida, Louisiana, Tennessee, Kentucky, and Missouri, where it occurs almost throughout the year, but most commonly in September and October. During this work it has been taken in Missouri, Tennessee, Illinois, North Carolina, Florida and Connecticut. It is interesting to note that these records are limited to the eastern states.

Complete descriptions of the adults may be found in the works of Banks (2), Chapman (3) and further notes are given by Ball (1). The males (Figs. 12, 15) can be readily distinguished from the females (Fig. 7) by the elaborate, darkly-pigmented genitalia that are apparent on the dorsal side of the abdomen.

\footnotetext{
${ }^{1}$ Contribution No. 230 from the Entomological Laboratories of the University of Illinois. This paper was included as a part of a thesis submitted in partial fulfillment of the requirements for the Degree of Master of Science in Entomology in the Graduate School of the University of Illinois, 1941.

${ }^{2}$ I wish to express my appreciation of the suggestions made by Professors C. L. Metcalf and W. V. Balduf during this work. Thanks are also due Dr. A. B. Gurney of the U. S. Bureau of Entomology and Plant Quarantine for determination of the species concerned.
} 
Only two variations in wing venation were found on the many specimens examined. Figure 10 shows a malformed short wing, that appeared on two individuals, the opposite wing being normal. Figure 11 illustrates the one case where peculiar venation was found in an otherwise normal wing. The extremity of $R_{4+5}$ is bent and $M_{1}$ does not reach the margin of the wing. Figure 14 is a normal wing. A greater degree of stability in wing venation is apparent in this genus because anomalies have rarely appeared among the individuals of $E$. californicus that have been raised on corn sheaths in the laboratory. Perhaps this lack of variability accounts for the fact that the genus is limited to two species in the United States.

E. pumilis first attracted my attention in October, 1938 when it was found in great numbers infesting the ears of corn in fields at Lawrenceville, Ill. During this work it has been taken from dry alfalfa stubble, dry grass, dead Viburnum, bamboo furniture, dried leaves of oak, maple, elm and palm. Habitats previously reported were dead oak leaves, straw and debris indoors, and windows of a cattle barn.

Of the thirty-five species in the family Cæciliidæ recorded from the United States this is one of twenty-two for which both males and females are known. The two species of Ectopsocus have both sexes known, but it is interesting to note that both males and females of the related species $E$. californicus have been taken only in California, while the females alone have been collected from Connecticut, New York, Virginia, Kentucky, North Carolina, Tennessee, Georgia and Florida. From work done by McClure (4) on the life history of E. californicus on palms in the University of Illinois greenhouses, and from my observations of this species in corn sheath cultures it is evident that $E$. californicus reproduces parthenogenetically and males do not occur. This information, along with collection records, suggests that $E$. californicus might be parthenogenetic in the East. It is interesting to note that the known distribution of the eastern parthenogentic (?) strain of $E$. californicus coincides almost state for state with that of $E$. pumilis. The sex ratio of $E$. pumilis was 0.5 and reproduction by parthenogenesis was not observed at any time.

Mating. - Copulation was observed several times, but the procedure varied to some extent each time. Sometimes the male just approached the female from the side, and backed into the 
mating position. On other occasions they approached each other and bumped head-on several times and furiously rubbed their heads together; then the male tried to approach the female from the side. The female raised the anterior part of her body and the male backed under with his wings erect. The female was directly above the male, but when the genitalia were united she side-stepped and the male's wings dropped back and rested across hers. They remained perfectly motionless, except for an occasional twitch of the palpi or antennæ, for twenty-two minutes. Usually the male started to walk first and when he stopped the female started. This brought them almost to a $180^{\circ}$ angle, facing in opposite directions. Each tried to go its way, with the result that the male usually dragged the female a short distance. Then they separated. A few minutes later the male approached as before, then stood still and appeared to rapidly raise his abdomen and head and rock forward and backward. It was not possible to determine if the tip of the abdomen or labium touched the substratum during these rapid motions. The male again approached the female and, failing to regain the mating position, went through these movements again. The genitalia of the male remained exposed for some time after mating (Fig. 13).

Copulation apparently did not occur within twenty-four hours after both sexes had moulted to the adult. Eggs deposited by females exposed to males for that period only did not hatch. In several instances adult males were observed trying to copulate with nymphs in the sixth instar.

Oviposition. - Eggs were found in the field in the fall and late spring on the inside of the corn sheaths (Fig. 8). They were most commonly found on the sheaths about four or five feet up on the stalk. The lower sheaths apparently fitted too tightly around the stalk, making it almost impossible for the cæciliids to crawl under the sheath. Near the top of the stalk the inner surface of the sheaths is exposed, offering little protection from the weather; so eggs were seldom found there. In late fall the eggs were sometimes found on exposed ears especially around kernels injured by the corn earworm. In late summer eggs were found on the drying leaves (Fig. 9) in the tunnel formed by the midrib and especially around caked pollen.

Eggs were laid in groups of one to sixteen, most commonly four to eight with an average of about six. The females seemed 
to prefer the smooth surface of the glass, because the eggs were deposited on the glass and cork more often than on the corn in the rearing cages, which are described by the writer, Sommerman (5).

When males were continually present, egg-laying started from two to four days after moulting to the adult, and continued two to four weeks, but eggs were not always deposited each day. The number of eggs in the first group deposited ranged from three to nine, and as the end of the oviposition period approached the number did not always dwindle. The number of egg masses per individual ranged from one to fourteen. There seemed to be a tendency to add eggs to previously deposited masses, resulting in fewer masses with a larger number of eggs per mass. Some females also scattered individual eggs. Material collected in the field indicated that the eggs were usually deposited in masses. There did not appear to be any particular production peak, the number varying from day to day without any gradual increase or decline. The maximum number of eggs deposited by any female was 92 . Death usually occurred five or six days after oviposition ceased.

Non-fertilized females usually deposited their first eggs from three to eight days after the last moult. Fifty was the maximum number laid by any virgin. None of these ever hatched. After oviposition ceased these females continued to live up to twenty-four days, making the adult stage for virgins usually about forty-three days, whereas the adult stage for fertilized females lasted about twenty-one days. Adult males usually lived about thirty-nine days but one male was collected in the field April 9, 1940 and died June 15, having lived sixty-seven days in a rearing tube. It is probable that this male had also passed the winter as an adult.

The process of oviposition is similar to that described for Cacilius manteri Sommerman (6). Eggs are deposited in masses and silk threads are spread over them but not in a dense sheet as in $C$. manteri or E. californicus. The silk threads are numerous. They criss-cross at various heights forming a loose network. The females wander about after depositing each egg. Within thirty minutes one female had deposited a mass of six eggs, and had started to cover them with silk. She rapidly turned and turned, fastening the threads here and there, and within four minutes had completely covered the mass and wandered away. 
Egg Stage. - Eggs (Fig. 1) are oval and flattened only on the surface contacting another object. The shells are smooth and shiny. Measurements of fifteen eggs chosen at random averaged $0.388 \mathrm{~mm}$. in length and $0.208 \mathrm{~mm}$. in width. The eggs were white when first laid, but turned a creamy yellow as development progressed. This change in color made the eggs still more difficult to find because they blended with the dried sheaths. They are easily overlooked because the silk is not dense enough to shine as it does in E. californicus or C. manteri.

Embryonic development was easy to observe in this species. The chorion and vitelline membrane remained practically transparent so the eyes of the embryo could be seen clearly on the fifth day of development, which was the day before hatching. Fifteen egg masses kept under laboratory conditions hatched on the sixth day. As the time for hatching approaches, the eggs become a little darker and the chorion wrinkles to the form of the body and appendages (Fig. 2). The embryo is ventral side up and the head, eyes, antennæ, legs and tip of the abdomen are easily visible. The arms of the egg burster (Fig. 4) stretch across the front of the head with the center puncturing shaft projecting posteriorly toward the clypeus. The heads of several individuals were observed pulsating before the chorions were broken, and in one case as much as eight hours before. This activity, spasmodic at first, occurs at more regular intervals until at the time the chorion splits the top of the head is pulsating regularly. Air bubbles appeared to be passing into the embryo through the mouth before the split in the chorion could be seen on the anterior end of the egg.

Hatching. - The pronymph, within its membrane, slipped from the chorion and vitelline membrane with no apparent effort at first, then as it rose it swayed back and forth. Fifteen minutes after the chorion was noticeably broken the egg burster punctured the pronymphal membrane. This differs from the report of Wachter (8) who states that the egg burster ruptures the chorion and that the vitelline membrane is broken by internal pressure. This puncture lengthened to a slit that continued to progress toward the eyes. It required another fifteen minutes before the head was completely free of the pronymphal membrane. At this time bubbles of air were passing into the head, which was becoming transparent. Thirty-five minutes from the time hatching started the head, thorax and most of the abdomen were out of the shell, and two minutes later the anten- 
næ and legs were free. Forty-two minutes from the start the nymph dropped down and stood beside the chorion. At this time the pulsations on the vertex could still occasionally be seen, and the bubble of air in the head extended anteriorly as far as the eyes. The segments of the abdomen were telescoping into their normal position. One hour after hatching started, the bubble in the head had almost completely disappeared. Several other individuals completed hatching in twenty-five and thirty minutes. The pronymphal exuviæ bearing the egg burster always remained partly extruded from the chorion.

Postembryonic Development. - The nymphs (Figs. 3, 5, 6) are buff with slightly darker appendages during the early instars and gradually become light brown. There are bristle-like setæ on the head and thorax. The dull color of the abdomen gives this species a characteristic velvety appearance. The antennæ are eight-segmented in the first instar (Fig. 3) and thirteensegmented thereafter. The wing pads appear in the third instar (Fig. 5) and the forewings approximately double their length with each successive moult. The sexes of the sixth instar nymphs can easily be distinguished because the asymmetrical genitalia of the male show through on the dorsal surface of the abdomen (Fig. 6). The duration of the six instar periods was as follows: first, 2.3 days; second, 2.4 days; third, 2.4 days; fourth, 2.7 days; fifth, 2.8 days and the sixth, 4.4 days. Apparently the last instar period is longer than any of the others, which is also true in $C$. manteri (6). The measurements in the following table were taken from ten preserved specimens in each instar:

\begin{tabular}{ccccccccc}
\hline \hline Instar & $\begin{array}{c}\text { First } \\
\mathrm{mm} .\end{array}$ & $\begin{array}{c}\text { Second } \\
\mathrm{mm} .\end{array}$ & $\begin{array}{c}\text { Third } \\
\mathrm{mm} .\end{array}$ & $\begin{array}{c}\text { Fourth } \\
\mathrm{mm} .\end{array}$ & $\begin{array}{c}\text { Fifth } \\
\mathrm{mm} .\end{array}$ & $\begin{array}{c}\text { Sixth } \\
\mathrm{mm} .\end{array}$ & $\begin{array}{c}\text { Adult } \\
\mathrm{mm} .\end{array}$ \\
\hline Head width $\ldots \ldots \ldots \ldots$ & 0.190 & 0.250 & 0.293 & 0.375 & 0.450 & 0.507 & 0.552 \\
Antennal length & $\ldots \ldots$ & 0.338 & 0.440 & 0.512 & 0.627 & 0.763 & 0.900 & 1.097 \\
Forewing length $\ldots \ldots$ & $\ldots \ldots$ & $\ldots \ldots$ & 0.094 & 0.175 & 0.333 & 0.616 & $\mathbf{1 . 6 0 7}$ \\
\hline \hline
\end{tabular}

The complete nymphal period averaged 17.3 days with a minimum of twelve and a maximum of twenty-seven. The nymphal period could probably be lengthened still more if feeding conditions were poor, because this species, like Lachesilla nubilis (Aaron), eats the epidermis and mesophyll of the sheaths when fungus is scarce. The total length of all the life stages was usually about 53 days. 
Moulting. - Often the nymphs ate their exuviæ, thus making it difficult to determine moults in cases where measuring was impossible. The majority of the exuviæ were in a vertical position with the head down, but some were horizontal. Moulting seemed to be the same as that described for $C$. manteri (6). The epidermis split along the top of the thorax and head. The nymph arched up, with the antennæ held down along the sides of the body. The head was finally freed and gradually the nymph rose until it was actually resting on the end of its abdomen, although the tarsi of the exuviæ were in contact with the substratum. When almost vertical the antennæ were released, then the legs. All this time air bubbles were being swallowed and the abdomen stretched out. After moving the legs it bent over, freeing the tip of the abdomen, and stood beside the exuviæ. After a short time the abdomen contracted to its normal length. One adult was observed from the time it first freed its legs from the exuviæ until its wings were completely unfolded. Five minutes after freeing the legs it walked from the exuviæ. The wings were beginning to unfold; so it turned around to a vertical position with the head up. In twelve minutes the wings were completely straightened and were the same light color throughout. After the third instar one can determine when moulting will occur because the thick wing pads stick out from the body as in Figure 6.

Habits. - Under laboratory conditions the nymphs and adults eat fungi, epidermis and mesophyll of the corn sheaths, pollen, embryo and starch of broken corn kernels, exuviæ, and dead of their own kind. This species seemed to get along very well on the embryo and starch of the corn kernels. In some cases when they finished there was nothing left but the hard yellow seed coat of the kernel. Silk is deposited by the nymphs and adults. Although the quantity produced by $E$. pumilis is considered rather conspicuous it is a small amount in comparison to that deposited by E. californicus. E. pumilis, like $C$. manteri, gave a sudden start when the cotton plugs in the rearing cages were moistened, and they usually pushed their mandibles into the cotton and took water from the plugs. There seemed to be a tendency for both the nymphs and adults to walk upward, if confronted with a vertical surface. This negative geotropism made this species easy to handle. If a glass tube were placed over an escaped nymph or adult it immediately 
walked up the side of the glass to the cotton plug. Other species sometimes had to be coaxed for a long time before they would walk upon a piece of corn sheath. This habit made it easy to transfer cultures from an old cylinder to a freshly prepared one. This species was successfully reared both in colony and individual cultures as described by Sommerman (5).

The adults exhibited somewhat regular periods of extreme activity. This was especially noticeable in cultures decidedly overcrowded (i.e., in comparison to any conditions normally found in the field). Late at night they became active but the cause is not known. They may have been stimulated by hunger, temperature, light from the desk lamp, or perhaps it was just a daily rhythm.

Overwintering. - This species was numerous on corn plants only in the fall. The heaviest infestation encountered occurred at Lawrenceville, Ill., in October 1938. In December 1939 it was numerous in a cornfield at Urbana, and was the common species found on corn at Mt. Carmel, Conn., during the same month. Eggs were not easy to find. Those taken in the field from December to April did not hatch when brought into the laboratory or when left out of doors. Usually eggs found during the winter were straw-colored and withered. Adults taken from the field December 30, 1939 at Mt. Carmel, Conn., deposited fertile eggs within two days after being brought in from out of doors. Living nymphs or adults were not taken in the field between January first and April first. An active male that had probably overwintered was found in the sheath on an uprooted corn stalk April 9, 1940.

On December 12, 1939 some nymphs and adults of $E$. pumilis were put in a tube and left out of doors. February 6 they were transferred out of doors to a clean tube. On April 1 an adult male, female and three nymphs were still alive. The cotton plug in the tube was moistened and they all drank readily. By April 9 these individuals had become active and their bodies were plump. By April 16 the overwintering female had deposited a mass of ten eggs. These eggs were taken into the laboratory for rearing, to see if the change from variable outof-doors temperatures to the abnormal indoor temperature would interfere with hatching. Seven of the ten hatched and all the nymphs matured. On April 21 one of the overwintering nymphs moulted to an adult and the overwintering female had 
also laid a group of eleven more eggs. These eggs were left out of doors and they hatched May 4. By May 12 these nymphs had reached the third instar. By May 25 they were in the sixth instar. The overwintering nymphs matured and deposited eggs that hatched, their nymphs likewise maturing. The overwintering nymphs and adults, and the unsuccessful attempts to hatch overwintering eggs suggest that a few nymphs or adults manage to survive the winter and continue their normal activities in the spring. They were not found during late June and July, but on August 1 adults and eggs were taken on the dried leaves of new corn.

Parasitism. - Groups of E. pumilis eggs were exposed to adults of Alaptus cacilii Girault (Hym., Mymaridæ) that had emerged from the eggs of Cacilius aurantiacus Hagen. Various groups of eggs were exposed on April 1, 5 and 11, but the eggs did not hatch and parasites did not emerge. The parasites were not definitely observed ovipositing in these eggs but they did walk over them. Other groups of eggs laid by the same female, not exposed to the parasites, hatched and matured normally. This scanty information suggests that $A$. cacilii oviposited in the eggs, that the embryo was destroyed and that conditions were not favorable for the complete development of the parasites; so neither emerged. It is interesting to note that Spruyt (7) records Alaptus cacilii from the eggs of Ectopsocus californicus (Banks), the other species of this genus in the United States, and which is also parasitized by Alaptus psocidivorus Gahan.

Summary. - Adults of Ectopsocus pumilis have been taken in many of the eastern states as far west as Missouri. Both sexes are known and the sex ratio is 0.5. The eggs are smoothshelled and are laid in masses covered with a loose network of threads. The nymphs and adults feed on fungus, pollen, starch and embryos of the corn kernels and on the corn sheaths. The egg stage requires six days. The egg burster, apparently on the inside of the pronymphal membrane punctures the latter, while the chorion and vitelline membrane are probably broken by internal pressure. The nymphs swallow air bubbles at hatching and at moulting. The pronymphal membrane, with the egg burster attached, is always found protruding from the chorion after hatching. The antennæ are eight-segmented in the first instar and thirteen-segmented thereafter. Wing pads appear on 
the third instar and about double their length with each moult. During moulting the nymphs are in a vertical position with the head down. The nymphal stage requires about seventeen days and the adult stage lasts about thirty days. The usual life span including the period within the egg is fifty-three days. Silk is deposited by all nymphs and adults. Winter is probably spent in the adult or nymphal stage.

\section{Literature Cited}

1. Ball, A. Descriptive Note Concerning an Ectopsocus From the United States, Psocoptera, Peripsocidæ. Mem. Soc. Ent. Belgique, Vol. 23, p. 188, Pl. VI, figs. 1-6. 1930-31.

2. Banks, N. New Neuropteroid Insects, Peripsocus pumilis sp. nov. Bull. Mus. Comp. Zool., Vol. 64, No. 3, p. 313, Pl. VI, fig. 79. 1920.

3. Chapman, P. J. Corrodentia of the United States of America: 1. Suborder Isotecnomera. Journ. New York Ent. Soc., Vol. 38, pp. 219-290, 319-403, 10 Pls. 1930.

4. McClure, H. E. Psocid Habits. Ent. News, Vol. 47, pp. 113-118, 143-146. 1936.

5. Sommerman, K. M. Rearing Technique For Corrodentia. Ent. News, vol. 45, pp. 29-39. 1943.

6. Description and Bionomics of Cacilius manteri $\mathrm{n}$. sp. (Corrodentia). Proc. Ent. Soc. of Washington, vol. 53, pp. 259-261. 1942.

7. Spruyt, F. J. Notes on Alaptus psocidivorus Gahan, A New Species of Mymaridæ (Hymenoptera). Pan-Pacific Ent., Vol. 3, No. 4, pp. 182-184. April, 1927.

8. Wachter, S. The Hatching of the Eggs of Peripsocus californicus Banks. PanPacific Ent., Vol. 2, No. 2, pp. 87-89. Oct., 1925.

\section{EXPLANATION OF PLATES}

\section{Plate V.}

Figure 1. Egg mass covered with silk threads.

Figure 2. Mature egg.

Figure 3. First instar (dorsal view).

Figure 4. Egg burster (enlarged).

Figure 5. Third instar (dorsal view).

Figure 6. Sixth instar (dorsal view).

Figure 7. Female (lateral view).

\section{Plate VI.}

(Scale of enlargement applies only to Figures 12 and 15.)

Figure 8. Corn sheath.

Figure 9. Corn leaf.

Figure 10. Malformed short wing.

Figure 11. Anomalous wing.

Figure 12. Male (dorsal view).

Figure 13. Protruding male genitalia (dorsal view).

Figure 14. Normal wing.

Figure 15. Male (lateral view). 


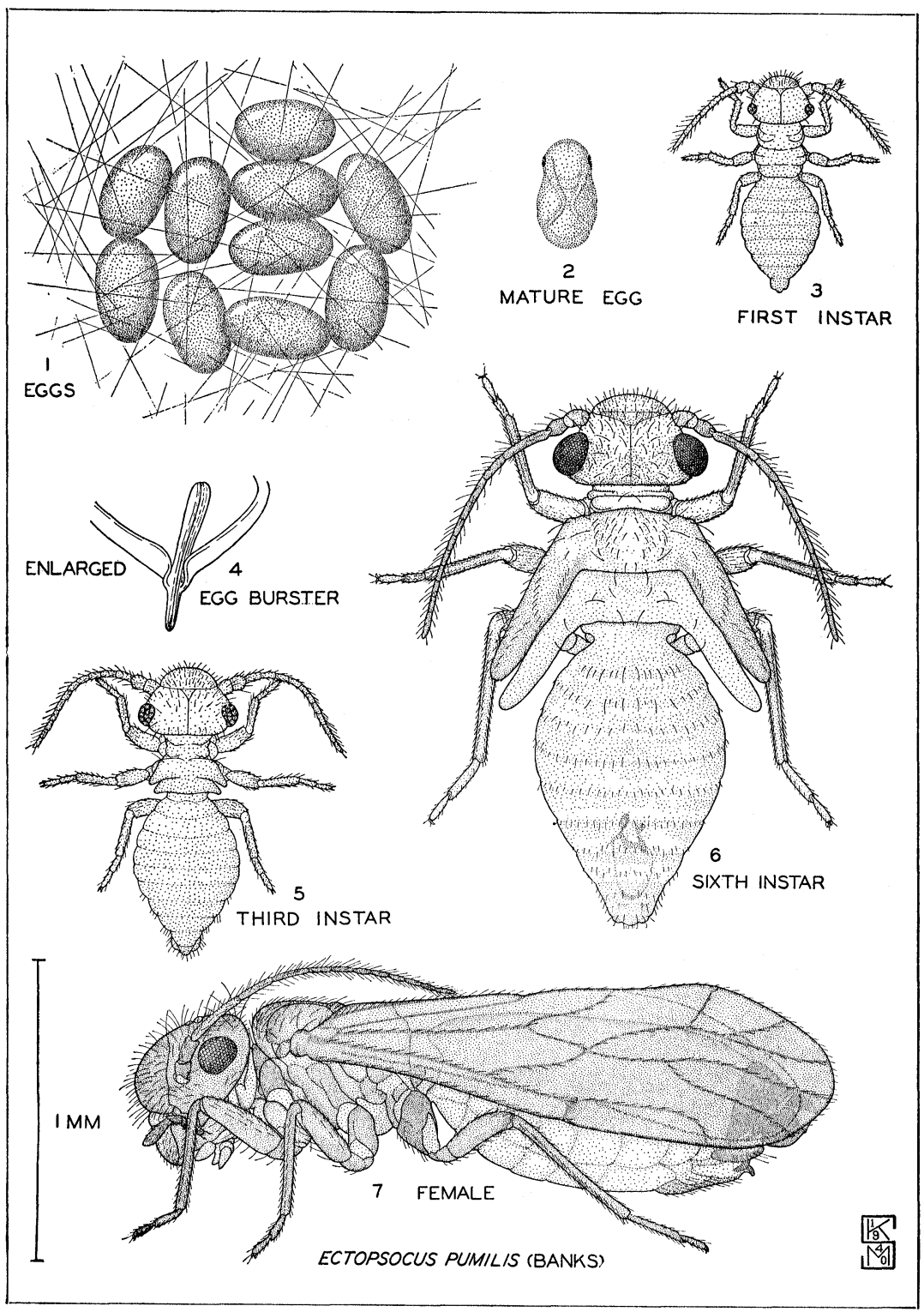

Sommerman - Ectopsocus pumilis 


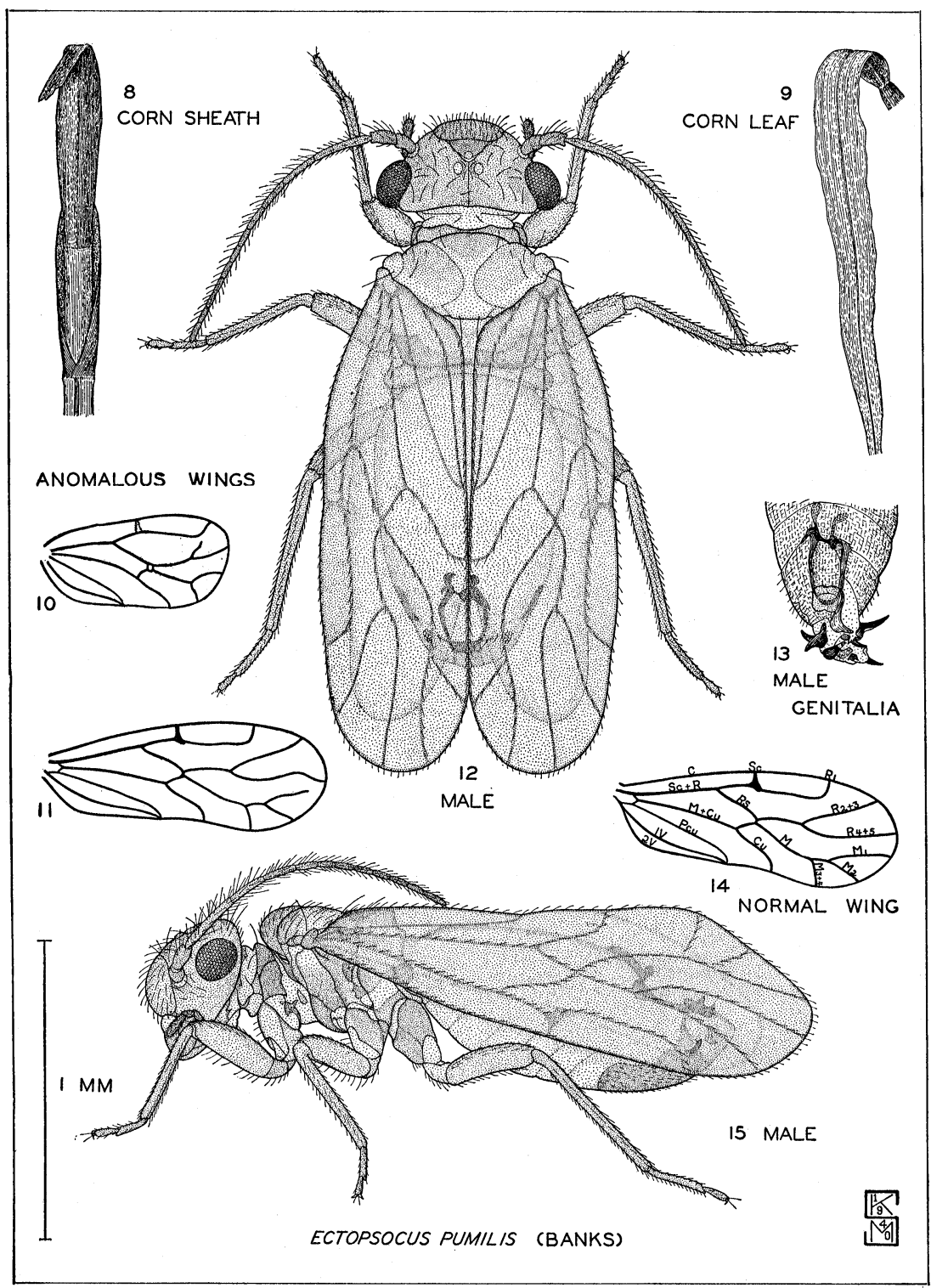

Sommerman - Ectopsocus pumilis 

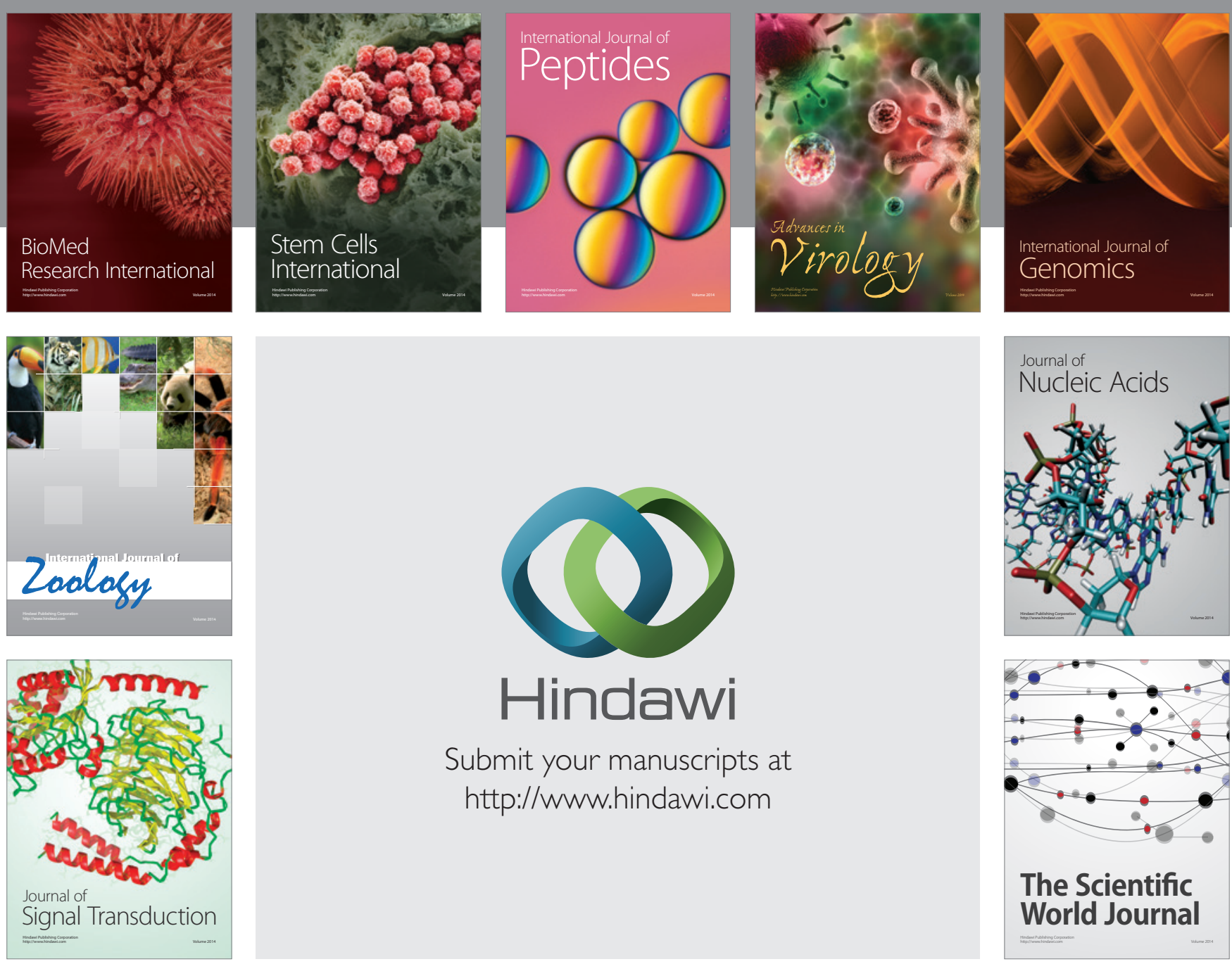

Submit your manuscripts at

http://www.hindawi.com
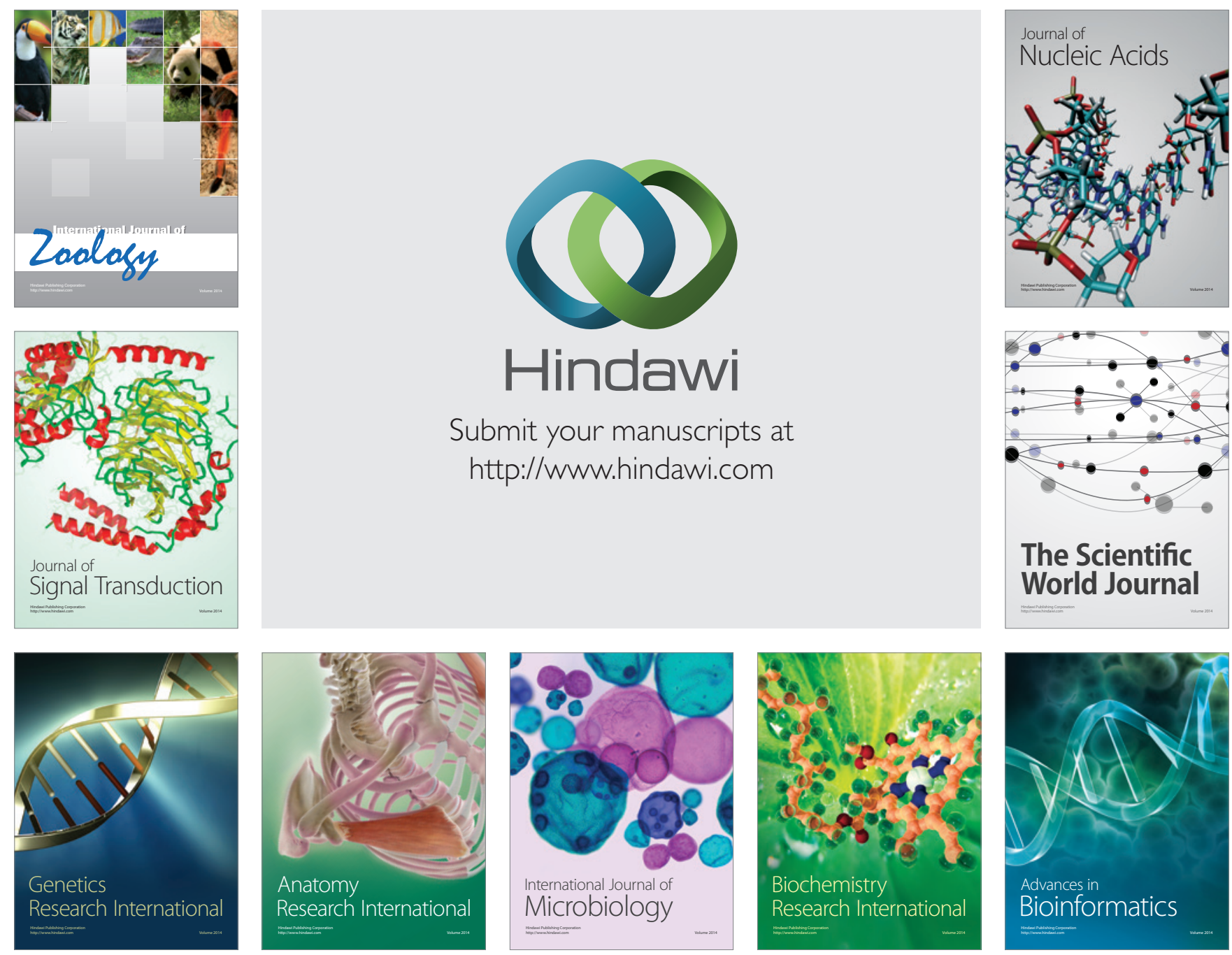

The Scientific World Journal
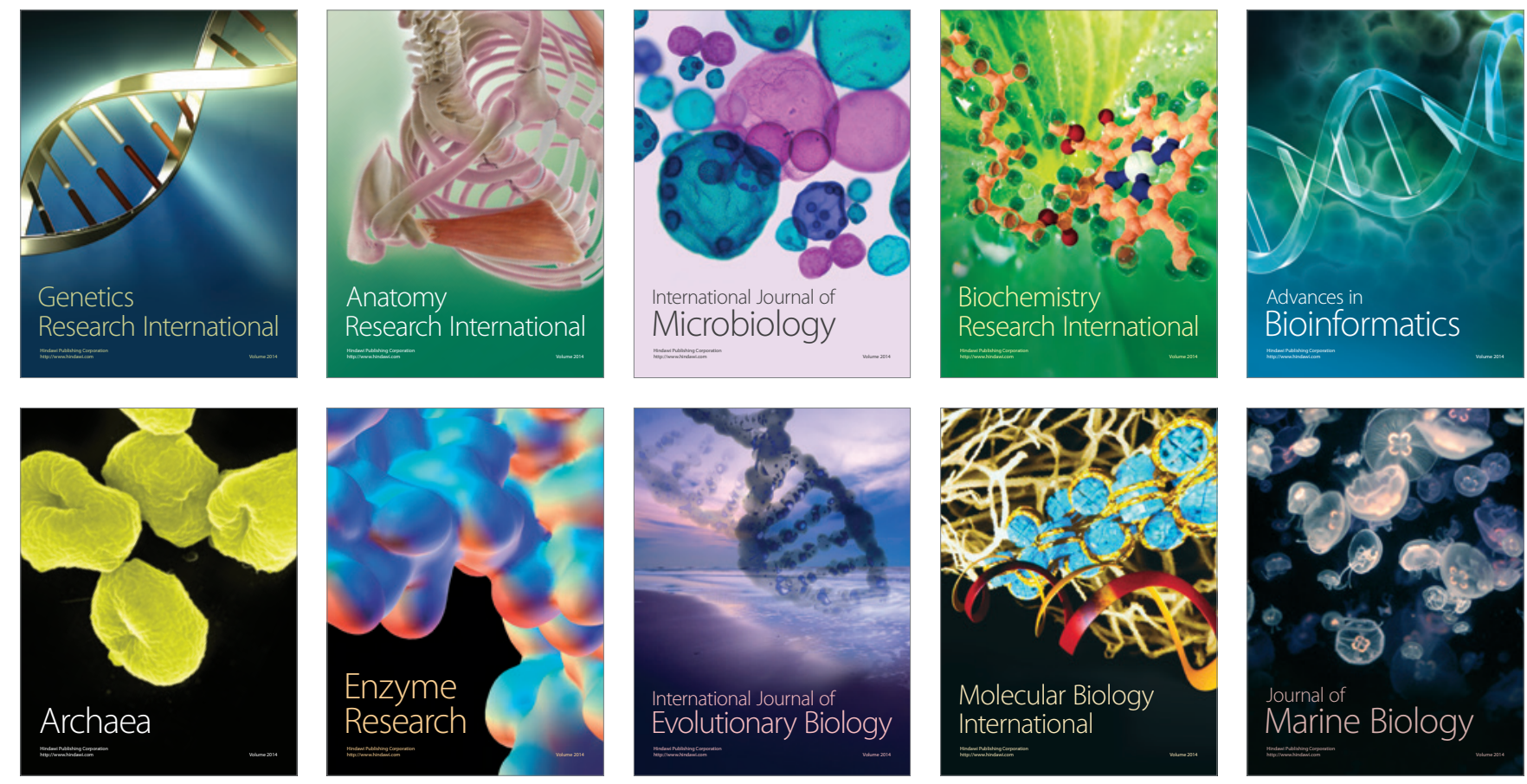